\title{
Myocarditis-associated necrotizing coronary vasculitis: incidence, cause, and outcome
}

\author{
Andrea Frustaci ${ }^{1,2}$, Maria Alfarano ${ }^{1}$, Romina Verardo $\mathbb{1}^{2}{ }^{2}$, Chiara Agrati $\mathbb{( D}^{3}$, \\ Rita Casetti ${ }^{3}$, Fabio Miraldi $\mathbb{1}^{1}{ }^{1}$, Nicola Galea $\mathbb{1}^{4}{ }^{4}$, Claudio Letizia ${ }^{5}$, and \\ Cristina Chimenti (1) ${ }^{1,2}$
}

\begin{abstract}
${ }^{1}$ Department of Clinical, Internal, Anesthesiologist and Cardiovascular Sciences, Sapienza University, Viale del Policlinico 155, 00161 Rome, Italy; ${ }^{2}$ Cellular and Molecular Cardiology Lab, IRCCS “Lazzaro Spallanzani”, Via Portuense, 292, 00149 Rome, Italy; ${ }^{3}$ Cellular Immunology Laboratory, IRCCS “Lazzaro Spallanzani”, Via Portuense, 292, 00149 Rome, Italy; ${ }^{4}$ Department of Experimental Medicine, Sapienza University, Viale del Policlinico 155, 00161 Rome, Italy and ${ }^{5}$ Department of Translation Medicine and Precision, Sapienza University, Viale del Policlinico 155, 00161 Rome, Italy
\end{abstract}

Received 24 April 2020; revised 25 June 2020; editorial decision 2 November 2020; accepted 26 November 2020

\begin{abstract}
Aims
Necrotizing coronary vasculitis (NCV) is a rare entity usually associated to myocarditis which incidence, cause, and response to therapy is unreported.

Methods and results

\section{Conclusion}

Among 1916 patients with biopsy-proven myocarditis, 30 had NCV. Endomyocardial samples were retrospectively investigated with immunohistochemistry for toll-like receptor 4 (TLR4) and real-time polymerase chain reaction (PCR) for viral genomes. Serum samples were processed for anti-heart autoantibodies (Abs), IL-1 $\beta$, IL-6, IL-8, tumour necrosis factor (TNF)- $\alpha$. Identification of an immunologic pathway (including virus-negativity, TLR4-, and Ab-positivity) was followed by immunosuppression. Myocarditis-NCV cohort was followed for 6 months with 2D-echo and/or cardiac magnetic resonance and compared with 60 Myocarditis patients and 30 controls. Increase in left ventricular ejection fraction $\geq 10 \%$ was classified as response to therapy. Control endomyocardial biopsy followed the end of treatment. Twenty-six Myocarditis-NCV patients presented with heart failure; four with electrical instability. Cause of Myocarditis-NCV included infectious agents (10\%) and immune-mediated causes (chest trauma 3\%; drug hypersensitivity $7 \%$; hypereosinophilic syndrome 3\%; primary autoimmune diseases 33\%, idiopathic 44\%). Abs were positive in immune-mediated Myocarditis-NCV and virus-negative Myocarditis; Myocarditis-NCV patients with Ab+ presented autoreactivity in vessel walls. Toll-like receptor 4 was overexpressed in immune-mediated forms and poorly detectable in viral. Interleukin-1 $\beta$ was significantly higher in Myocarditis-NCV than Myocarditis, the former presenting 24\% in-hospital mortality compared with $1.5 \%$ of Myocarditis cohort. Immunosuppression induced improvement of cardiac function in $88 \%$ of MyocarditisNCV and $86 \%$ of virus-negative Myocarditis patients.

Necrotizing coronary vasculitis is histologically detectable in $1.5 \%$ of Myocarditis. Necrotizing coronary vasculitis includes viral and immune-mediated causes. Intra-hospital mortality is $24 \%$. The immunologic pathway is associated with beneficial response to immunosuppression.
\end{abstract}

\footnotetext{
* Corresponding author. Tel: + 39065517 0520, Email: biocard@inmi.it

Published on behalf of the European Society of Cardiology. All rights reserved. ( ) The Author(s) 2020. For permissions, please email: journals.permissions@oup.com.

This is an Open Access article distributed under the terms of the Creative Commons Attribution Non-Commercial License (http://creativecommons.org/licenses/by-nc/4.0/),

which permits non-commercial re-use, distribution, and reproduction in any medium, provided the original work is properly cited. For commercial re-use, please contact

journals.permissions@oup.com
} 


\section{Graphical Abstract}

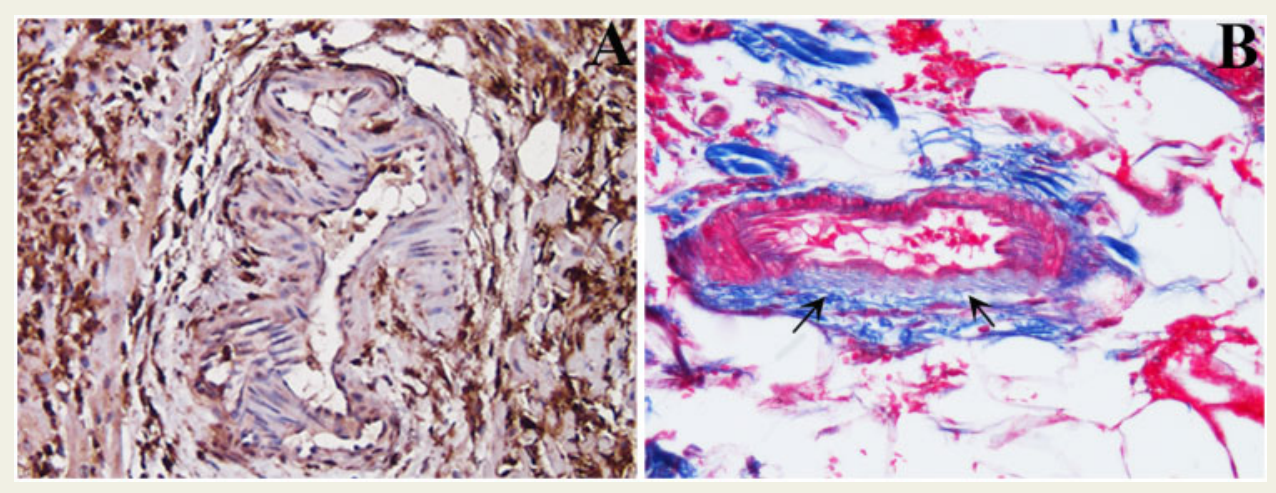

Keywords

Myocarditis • Vasculitis - Viral infection - Autoimmune disease

\section{Introduction}

Myocarditis is an inflammatory disease of the heart frequently resulting from viral infections that cause direct cardiac damage and/or post-viral immune-mediated responses. ${ }^{1}$ Beyond infections, myocarditis can be caused by a large variety of autoimmune disorders, drugs, and toxins. ${ }^{2}$ It is an important heart-specific inflammatory entity causing heart failure, chest pain, unexplained arrhythmias, and sudden death. Prognosis in myocarditis patients depends on the underlying aetiology. ${ }^{3}$ Rarely, myocarditis is associated with necrotizing vasculitis of intramural vessels.

Aim of this retrospective study is to report incidence, cause, and outcome based on the underlying condition and its specific treatment.

\section{Methods}

\section{Study population}

At our institution from January 1983 up to July 2019, 5180 patients underwent an endomyocardial biopsy (EBM) because of suspected cardiomyopathy or myocarditis. A histological diagnosis of myocarditis was obtained in $37 \%$ of cases (1916) on the basis of the current definition. ${ }^{4}$ Among them, a necrotizing coronary vasculitis (NCV), defined as associated inflammatory infiltration with necrosis of intramural vessel wall, was documented in 30 patients (1.5\%; 12 females and 18 males, with mean age of 47.7 years \pm 15 ). All patients included in the study presented a severe cardiac compromise and at histology extensive myocarditis with at least two intramural arterioles or small arteries involved. This cohort [myocarditis-associated necrotizing coronary vasculitis (MyocarditisNCV) patients] represents our study population. The study was approved by the local Ethics Committee and patients gave their informed consent.

Endomyocardial samples from all patients were retrospectively studied with histology, immunohistochemistry including myocardial expression of toll-like receptor 4 (TLR4) and real-time PCR for viral genomes. Serum samples were processed for anti-heart autoantibodies (Abs) and inflammatory cytokine profile. Myocarditis-NCV patients, defined as those presenting at histology CD3-positive T-lymphocytes $\geq 7$ cells $/ \mathrm{mm}^{2}$ associated to necrosis of adjacent myocytes with lymphocytic wall infiltration and necrosis of $\geq 2$ arterioles or small coronary arteries, were compared with a group of 60 consecutive patients with virus-positive and virus-negative lymphocytic myocarditis and a control group of 30 patients with mitral stenosis and normal left ventricular (LV) size and function, undergoing surgical repair.

\section{Clinical studies}

Clinical assessment, resting electrocardiogram (ECG), Holter monitoring, and 2D-echocardiography were performed at baseline in all patients. Cardiac catheterization, angiography, and left or biventricular EBM were also performed, after patients' informed consent.

Echocardiographic parameters were determined according to established criteria. ${ }^{5}$ Cardiac magnetic resonance (CMR) imaging with late gadolinium enhancement was performed in $45 \%$ of cases, because clinical conditions were not compatible with the CMR or because the patients were evaluated before 2000. Functional and morphological data were analysed according to the Lake Louise criteria. ${ }^{6}$

All patients received conventional medical treatment for heart failure and arrhythmias. ${ }^{7}$ In addition, immunosuppressive therapy, including $1 \mathrm{mg} / \mathrm{kg}$ prednisone daily for 4 weeks followed by $0.33 \mathrm{mg} / \mathrm{kg}$ daily for 5 months and $2 \mathrm{mg} / \mathrm{kg}$ azathioprine daily for 6 months, was performed in case of virus-negative inflammatory cardiomyopathy or identification of an immunologic pathway (virus-negative, TLR4-positive, anti-heart Abpositive) ${ }^{8}$ In case of specific primary autoimmune disorders (i.e. Systemic Lupus Erythematosus, Churg-Strauss syndrome, Takayasu arteritis and Giant cell myocarditis) other immunosuppressive regimens (cyclophosphamide, high-dose immunoglobulins, anakinra) were adopted. Patients were followed for 6 months and absolute increase of $\geq 10 \%$ in the left ventricular ejection fraction (LVEF) was classified as response to therapy.

Endomyocardial biopsies (3-6 fragments) were drawn in the septalapical region of left or both ventricles. 9 Samples were either fixed in formalin and paraffin-embedded for histopathology and immunohistochemistry or snap frozen for molecular biology. Histologic diagnosis of 
myocarditis was performed according to the Dallas criteria. ${ }^{10}$ For the phenotypic characterization of the inflammatory infiltrates, immunohistochemistry for Cluster of Differentiation (CD)3, CD20, CD43, CD45RO, and CD68 was performed (all Dako, Carpinteria, CA, USA). The presence of an inflammatory infiltrate $\geq 14$ leucocytes $/ \mathrm{mm}^{2}$ including up to 4 monocytes $/ \mathrm{mm}^{2}$, with the presence of CD3-positive T-lymphocytes $\geq 7$ cells $/ \mathrm{mm}^{2}$ associated with evidence of degeneration and/or necrosis of the adjacent cardiomyocytes, was considered diagnostic for myocarditis. ${ }^{4}$ The number of CD3-positive cells was manually counted using a tally counter on high power field $(\times 400)$ scanning the entire slide. The area of tissue samples was measured by means of a computerized system (Imaging Software/NIS-Elements AR 4.30, Nikon Instruments Inc., Melville, NY, USA). The number of CD3-positive cells was expressed as number of cells per square millimetre. Morphometric evaluation was performed by a pathologist blinded to clinical data. Moreover, it was determined the myocardial expression of TLR4, as already described. ${ }^{11}$ The endothelial cells of intramural vessel wall were identified by means of CD31 antibody (Monoclonal Mouse Anti-Human CD31, Endothelial cells, Dako Denmark A/S, 1:10).

In all patients at baseline, a real-time PCR analysis ${ }^{12}$ for the most common cardiotropic viruses (adenovirus, enterovirus, influenza $A$ and $B$ viruses, Epstein-Barr virus, Parvovirus B19 (PVB19), Hepatitis C virus, Cytomegalovirus, Human Herpes Virus 6, Herpes Simplex virus A and B) was performed.

\section{Serum studies}

Serum samples were processed for anti-heart $A b s$ and inflammatory cytokine profile including assessment of IL-1 $\beta$, IL-6, IL-8, tumour necrosis factor (TNF)- $\alpha$ (ELLA assay). ${ }^{13}$ The presence of circulating anti-heart Abs was evaluated by indirect immunofluorescence as previously described. ${ }^{14,15}$ Briefly, patient sera were tested with a substrate of $4-\mu \mathrm{m}$ thick unfixed cryostat sections of human atrium and intercostal skeletal muscle of blood group $O$ patients. The intensity of immunofluorescence of the positive control (known positive serum) at 1/40 dilution was used as the cut-off point for positivity. Omission of the patient serum and known negative serum was included in every assay (negative controls).

\section{Follow-up}

Clinical assessment, resting ECG, Holter monitoring, and 2D-echocardiography were performed at baseline, weekly during the 1st month, every 4 weeks for the subsequent 5 months. Cardiac magnetic resonance was repeated in $45 \%$ of cases at the end of the study. All patients had a control biopsy at the end of immunosuppressive therapy. Control histology, immunohistochemistry for inflammatory cells, and TLR4 were obtained. Serum control studies for anti-heart antibodies and quantification of inflammatory cytokines were also undertaken.

\section{Statistical analysis}

Quantitative measurements are expressed as mean \pm SD. A value of $P<0.05$ was considered as significant. Categorical data were presented as absolute frequencies and per cent values. Difference between two groups was determined by unpaired $t$-test for continuous variables and Fisher's exact test for categorical variables. Continuous variables are normally distributed. Multiple group comparisons were obtained for continuous variables with analysis of variance (ANOVA) and for categorical variables with $\chi^{2}$ test. Post-hoc analysis was performed using Bonferroni correction for continuous variables tested with ANOVA. The univariate and multivariable relationship among demographic, clinical, and echocardiographic data and presence of NCV and in-hospital mortality were also assessed.

\section{Results}

\section{Myocarditis-necrotizing coronary vasculitis patients}

An NCV has been histologically detected in 30 out of 1916 patients (1.5\%) with myocarditis. No complications resulted from EBM even when applied to a severely compromised left ventricle.

\section{Clinical manifestation and investigations}

Twenty-six (87\%) Myocarditis-NCV patients presented with heart failure or cardiogenic shock; $13 \%(n=4)$ with electrical instability. No differences were registered in terms of age and gender. Time to symptoms onset was variable from few days to some weeks manifesting with acute cardiogenic shock or progressive cardiac deterioration. Impairment of cardiac function was found in nearly $87 \%$ of patients, often requiring inotropic drugs and in 11 patients mechanical circulatory support (such as extracorporeal membrane oxygenation, ECMO). Of the latter, $64 \%$ had an LVEF $\leq 25 \%$ and LV end-diastolic diameter (LVEDD) $\geq 60 \mathrm{~mm}$. Two-dimensional echocardiography was performed in all patients at baseline and during follow-up. Cardiac magnetic resonance was performed in 45\% of cases, because clinical conditions were not compatible with the CMR or because the patients were evaluated before 2000; of these patients, Lake Louise criteria were suggestive of myocarditis in $78 \%$ of cases. Cardiac magnetic resonance did not find qualitative signal abnormalities suggesting the presence of NCV.

Coronary vessels were normal in all patients, left ventriculography showed the presence of thrombi at the LV apex in eight subjects and small aneurysms in LV apical and posterior segments in nine cases.

High-sensitivity Cardiac Troponin was more elevated in Myocarditis-NCV $(0.32 \pm 0.2 \mu \mathrm{g} / \mathrm{L})$ than Myocarditis cohort $(0.1 \pm 0.14 \mu \mathrm{g} / \mathrm{L})(P<0.01)$.

\section{Aetiology}

Myocarditis-NCV was infectious in three patients and the identified agents on cardiac tissue were Human Herpes Virus 2 (HHV2), Epstein-Barr Virus and in one case, a fatal PVB19-Toxoplasma gondii co-infection in an HIV-positive patient. In three patients, MyocarditisNCV was auto-reactive and caused by blunt chest trauma in a 41year-old football player and drug hypersensitivity in the other two patients, one of whom was under treatment with clozapine $250 \mathrm{mg} / \mathrm{d}$ for schizophrenia and the other with clomipramine $150 \mathrm{mg} / \mathrm{d}$ for depression; all these patients developed cardiogenic shock requiring inotropic support and ECMO. One patient had a hypereosinophilic syndrome. In 33\% of patients, Myocarditis-NCV was associated to a primary autoimmune disorder including polyarteritis nodosa $(n=1)$; systemic lupus erythematosus $(n=2)$; coeliac disease $(n=1)$; granulomatous polyangiitis $(n=1)$; Churg-Strauss syndrome $(n=1)$, Takayasu arteritis $(n=1)$; and giant cells myocarditis $(n=3)$. This cohort presented with severe clinical impairment presenting as restrictive cardiomyopathy, LV aneurysm and/or thrombosis, dilated cardiomyopathy (DCM), or cardiogenic shock. In the remaining $44 \%$ cases $(n=13)$, Myocarditis-NCV was classified as idiopathic. 


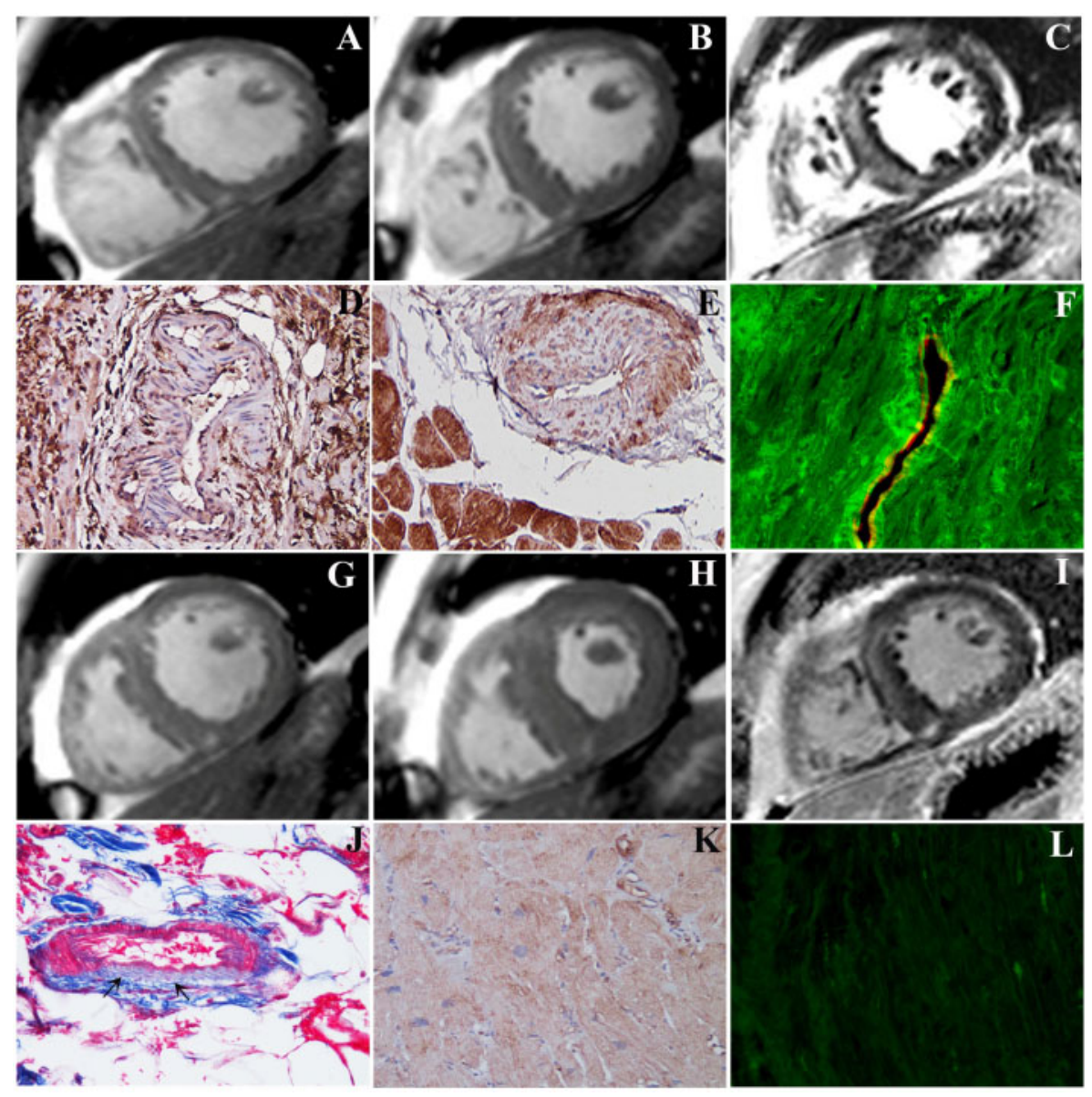

Figure I Immune-mediated myocarditis-associated necrotizing coronary vasculitis responding to immunosuppressive therapy. (A-C) Short-axis cardiac magnetic resonance showing remarkably dilated (A, EDV/BSA 124,7 mL/S2) and hypokinetic (B, ejection fraction 23\%,) left ventricle with extensive subepicardial late gadolinium enhancement $(C$ suggesting severe myocarditis. (D) Severe lymphocytic myocarditis with necrotizing vasculitis of an intramural coronary artery (immunohistochemistry with CD45Ro, 200×). (E) Necrotizing coronary vasculitis with overexpression of toll-like receptor 4 in cardiomyocytes and vascular smooth muscle cells suggesting an immune-mediated mechanism of damage (immunoperoxidase for tolllike receptor 4, 200×). (F) Positive anti-heart antibodies (FITC green fluorescence) with autoreactivity for vessel wall, as showed by the co-localization with CD 31 antigen (TRITC red immunostaining), 400x. (G-l) Control cardiac magnetic resonance after immunosuppressive therapy showing normalization of left ventricular end-diastolic dimension (G, EDV/BSA $86,5 \mathrm{~mL} / \mathrm{S} 2$ ), contractility ( $H$, ejection fraction rising from $23 \%$ to $52 \%$ ) and reduction with attenuation of late gadolinium enhancement $(I)$. ( $(-L)$ Control biopsy after 6-month immunosuppressive therapy showing healed myocarditis with reparative fibrosis of vessel wall (J, arrows, Masson trichrome, 200×), reduction of toll-like receptor 4 immunoreactivity ( $K$, immunoperoxidase for toll-like receptor 4, 200× magnification), and negativity of anti-heart antibodies ( $L$, indirect immunofluorescence).

\section{Endomyocardial biopsies and immunologic profile}

In all Myocarditis-NCV patients, histology showed extensive inflammatory infiltrates associated to cell necrosis (Figure 1D). Coronary intramural vessels were similarly infiltrated with necrosis of their wall (Figure 1D).

Myocarditis-NCV was classified as immune-mediated when antiheart Abs were positive, viruses in cardiac tissue were absent, myocardial TLR-4 was overexpressed and inflammatory cytokines (IL-1 $\beta$, IL-6, IL-8, TNF- $\alpha$ ) in serum samples were elevated. In particular, cardiac Abs were present in 27 (90\%) of myocarditis-NCV patients with partially organ-specific pattern of staining, consisting in a strongly positive fine striational pattern on human heart tissue and a weak positive fine striational pattern on human skeletal muscle. ${ }^{14}$ Interestingly, in patients in whom anti-heart Abs were positive, the immunofluorescence was extended to intramural coronary vessels' wall, as confirmed by co-localization for the endothelial antigen CD31 (Figures $1 \mathrm{~F}$ and 2) also TLR4 was overexpressed both in cardiomyocytes and in necrotized vessels (Figure 1E).

\section{Management and follow-up}

All patients received conventional medical treatment for heart failure and arrhythmias. Immune-mediated Myocarditis-NCV patients were treated with immunosuppression including $1 \mathrm{mg} / \mathrm{kg}$ prednisone daily for 4 weeks followed by $0.33 \mathrm{mg} / \mathrm{kg}$ daily for 5 months, and $2 \mathrm{mg} / \mathrm{kg}$ azathioprine daily for 6 months according to the Tailored Immosuppression in Inflammatory Cardiomyopathy (TIMIC) trial. ${ }^{8}$ The auto-reactive Myocarditis-NCV group was treated with highdose steroids and withdrawal of the culprit agent in case of drug 


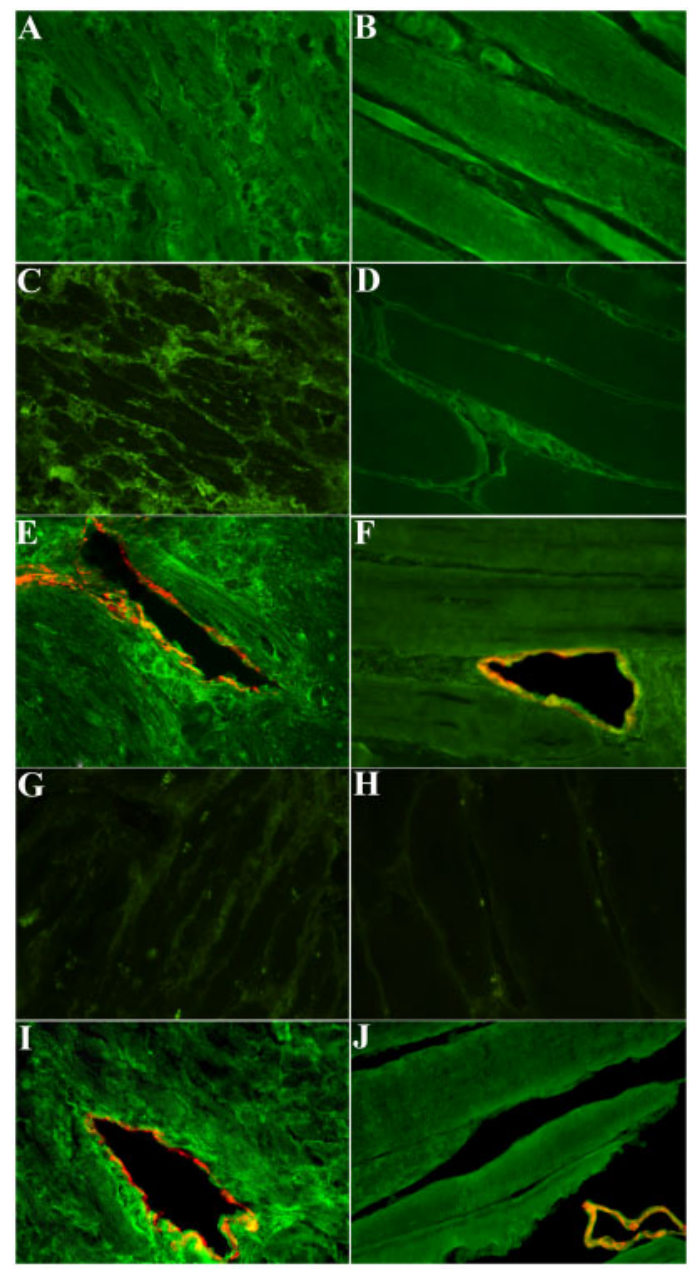

Figure 2 Anti-heart autoantibodies characterization: evidence for partially organ-specific pattern in patients with Myocarditisnecrotizing coronary vasculitis. (A) Positive partially organ-specific (fine striational) pattern of anti-heart autoantibodies on human heart (FITC green fluorescence, $400 \times$ ) in the serum of a patient with Myocarditis-necrotizing coronary vasculitis. (B) Weakly positive staining for anti-heart autoantibodies on skeletal muscle (FITC green fluorescence, $400 \times)$ in the serum of the same patient of $A$. (C) Anti-heart autoantibody-negative control serum on human heart; no cardiomyocyte staining is present (FITC green fluorescence, 400×). (D) Anti-heart autoantibody-negative control serum on human skeletal muscle; no myocyte staining is present (FITC green fluorescence, 400×). (E) Positive serum for anti-heart and anti-endothelial cells autoantibodies on human heart (FITC green fluorescence, $400 \times$ ) in a patient with Myocarditis-necrotizing coronary vasculitis. $(F)$ Positive serum for anti-heart and anti-endothelial cells autoantibodies on skeletal muscle (FITC green fluorescence, $400 \times$ ) in a patient with Myocarditis-necrotizing coronary vasculitis. $(G)$ Negative control serum for fluoresceinated secondary antibody on human heart (FITC green fluorescence, 400x). $(H)$ Negative control serum for fluoresceinated secondary antibody on skeletal muscle (FITC green fluorescence, 400×). (I) Positive control serum for anti-heart and anti-endothelial cell autoantibodies on human heart (FITC green fluorescence, 400×). () Positive control serum for anti-heart and anti-endothelial cell autoantibodies on human skeletal muscle (FITC green fluorescence, $400 \times$ ). hypersensitivity and subsequently showed full recovery of LV function. In the giant cell Myocarditis-NCV group $(n=3)$, an aggressive immunosuppressive treatment with high-dose steroids and azathioprine was administered (prednisolone iv $7 \mathrm{mg} / \mathrm{kg}$ for 3 days, followed by prednisone $1.5 \mathrm{mg} / \mathrm{kg} / \mathrm{d}$ orally for 2 weeks tapered to $1 \mathrm{mg} / \mathrm{kg} / \mathrm{d}$ for 4 weeks; then prednisone was reduced to $0.33 \mathrm{mg} / \mathrm{kg} / \mathrm{d}$ and azathioprine $2 \mathrm{mg} / \mathrm{kg} / \mathrm{d}$ was included in the treatment; after 6 months, steroids were tapered and withdrawn; azathioprine from the 6th month was reduced to $1 \mathrm{mg} / \mathrm{kg} / \mathrm{d}$ ); in two of these patients, cardiac function was totally recovered. Patients with primary autoimmune disorder received immunosuppressive therapy including steroids, azathioprine, and cyclophosphamide with complete resolution of myocarditis. One patient with virus-negative inflammatory cardiomyopathy and decompensated type 2 diabetes mellitus was treated with high-dose immunoglobulin and then with IL-1 $\beta$ inhibitor (anakinra) with improvement of ventricular function.

Two patients with immune-mediated Myocarditis-NCV were not treated with immunosuppression because death occurred because of cardiogenic shock or ventricular fibrillation.

Immunosuppression resulted in an improvement of cardiac function in 22 (88\%) out of 25 Myocarditis-NCV-treated patients. None of the patients on immunosuppression had major drug-related side effects requiring therapy withdrawal; minor adverse reaction as increased body weight, glucose blood level elevation and fluid retention requiring diet, oral anti-diabetic drugs or insulin administration, and diuretic dose adjustment were reported in $30 \%$ of cases.

Death occurred during hospitalization in seven patients with Myocarditis-NCV because of cardiogenic shock or cardiac arrest. Inhospital death (24\%) was remarkably higher than that $(1.5 \%)$ of Myocarditis cohort. Regarding aetiology, death occurred in the HIVpositive patient with PB19V-T. gondii co-infection, in the patient with $\mathrm{HHV} 2$ related-myocarditis because the viral infection caused a severe Myocarditis-NCV (Figure 3) and infiltration of cardiac conduction tissue and ganglia inducing ventricular fibrillation, in the patient with hypereosinophilic syndrome, in one patient with giant cells and in three patients with immune-mediated Myocarditis-NCV.

Control biopsy in patients receiving immunosuppressive therapy showed progression of inflammatory disease to healed myocarditis and vasculitis with disappearance of inflammatory cells, halting of tissue necrosis and myocardial and vessel reparative fibrosis, attenuated expression of TLR4 and negative anti-heart antibodies (Figure 1J-L).

In patients with virus-negative Myocarditis, immunosuppression induced an improvement of cardiac contractility in $86 \%$ of cases.

\section{Comparison between Myocarditis- necrotizing coronary vasculitis patients, M patients and controls}

Baseline clinical parameters and immunological pattern of Myocarditis-NCV patients compared with Myocarditis patients and normal controls are shown in Table 1 (overall $P$-values). Supplementary material online, Table shows the $P$-value for each comparison.

Cardiac magnetic resonance imaging did not detect any qualitative difference between Myocarditis-necrotizing coronary vasculitis and Myocarditis patients. 


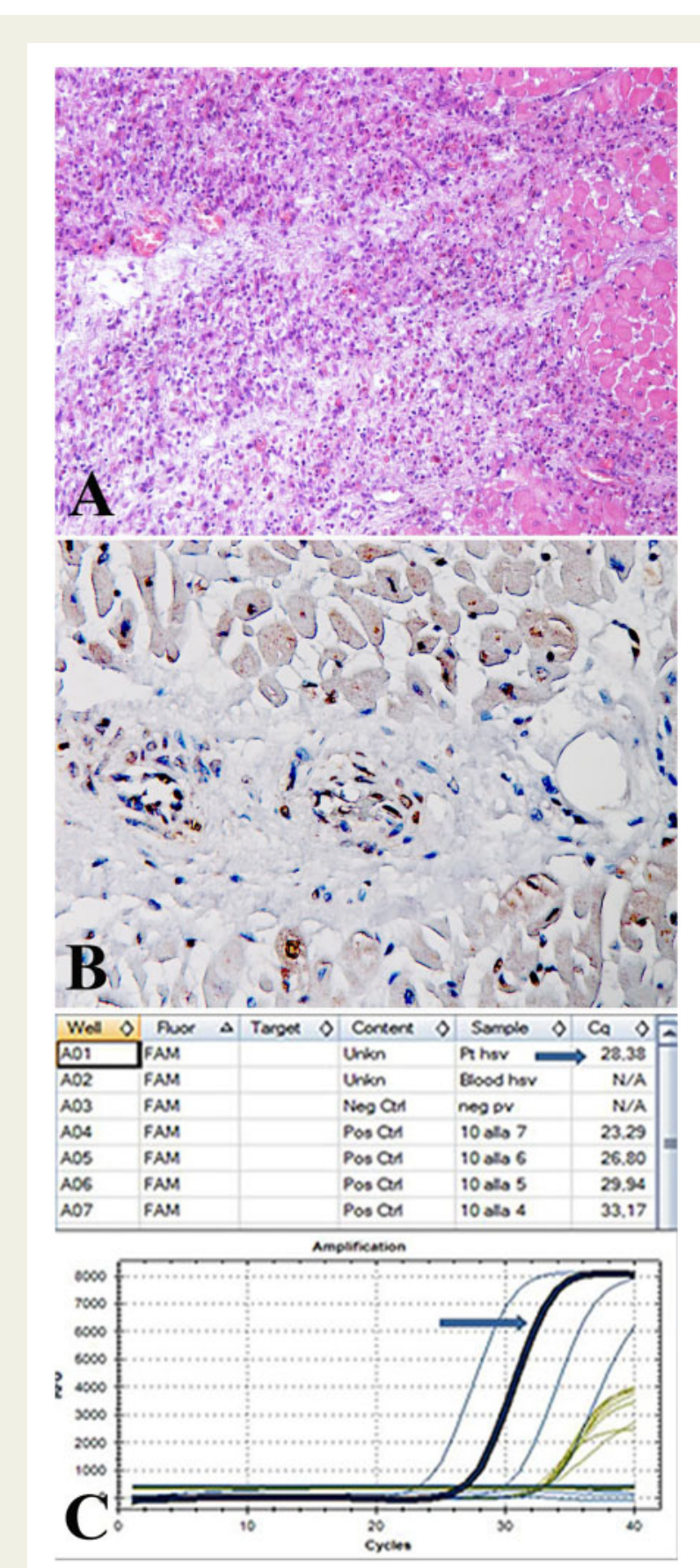

Figure 3 Post-mortem histologic and molecular study in a 33year woman died because of infectious myocarditis with necrotizing coronary vasculitis. (A) Massive lymphocytic myocarditis with extensive cell necrosis (H\&E 100×). (B) Necrotizing intramural coronary vasculitis with no expression of toll-like receptor 4 suggesting an infectious cause (immunohistochemistry for toll-like receptor 4, 200×). (C) Real-time PCR indicating a myocardial infection by Human Herpes Virus 2.

Anti-heart Abs were positive in all the immune-mediated Myocarditis$\mathrm{NCV}(n=27)$, and virus-negative Myocarditis $(n=55)$, while were negative in viral forms of myocarditis and in normal controls.
Myocardial expression of TLR4 was increased in the immunemediated forms and poorly detectable in the viral forms and in the control group (who did not show any sign of myocardial inflammation at histology). Circulating interleukins $1-\beta$ and IL-8 were higher in patients with Myocarditis-NCV $(2.82 \pm 8.0$ and $12.41 \pm 18.4 \mathrm{pg} / \mathrm{mL}$, respectively) in comparison with virus-negative Myocarditis patients $(0.57 \pm 0.34$ and $8.42 \pm 4.6 \mathrm{pg} / \mathrm{mL}$, respectively) and control group $(0.35 \pm 0.24$ and $3.27 \pm 0.7 \mathrm{pg} / \mathrm{mL}$, respectively). IL-6 and TNF- $\alpha$ did not show any statistical relevant difference between two groups (Myocarditis-NCV vs. Myocarditis).

Fisher's test showed a significant association between in-hospital mortality and the presence of NCV $(P=0.002)$.

In the univariate analysis, the variables that were significantly associated with in-hospital mortality among all Myocarditis patients with and without NCV were female gender (OR 4.8, 95\% Cl: 1.1-22, $P=0.041$ ), and presence of coronary necrotizing vasculitis (OR 17.9, 95\% Cl: 2.1-154, $P=0.008$ ) (Table 2). At multivariable analysis presence of coronary necrotizing vasculitis (OR 15.4, 95\% Cl: 0.7-71, $P=0.014)$, was confirmed to significantly predict in-hospital mortality.

A limitation for the validity of statistical analysis is that confidence interval for NCV is wide and it is likely related to the limited sample size.

\section{Discussion}

Myocarditis is a major cause of heart muscle disease concurring approximately to one-third of diagnoses obtained from EBM studies. ${ }^{9}$ Rarely it may complicate with inflammation of intramural vessels causing severe impairment of cardiac function and/or enhancement of electrical instability leading to increased in-hospital mortality. Its knowledge is limited to occasional, single case reports ${ }^{16-19}$ while extensive studies on incidence, cause, and outcome are not reported in literature. Myocarditis-NCV was recognized in our study in 1.5\% (30 cases) of 1916 consecutive patients with a histological diagnosis of myocarditis. Diagnosis of myocarditis followed the Dallas criteria ${ }^{10}$ implemented by immunohistochemical characterization of the inflammatory cells. In-hospital mortality was $24 \%$ compared with $1.5 \%$ occurred in 60 consecutive patients with isolated acute myocarditis. Elevated Myocarditis-NCV mortality was not preventable by use of ventricular assist device and/or ICD implantation confirming its grim prognosis.

Myocarditis-NCV was not distinguishable from myocarditis alone by CMR and its identification can only be obtained by EBM. On the other hand, it is recognized ${ }^{20}$ that even diagnostic CMR sensitivity for myocarditis while is high (>90\%) for infarct-like phenotype is limited (<50\%) for cardiomyopathic and arrhythmic presentation. In addition, CMR cannot influence myocarditis treatment as it does not provide details on histological, immunohistochemical, and molecular characterization of myocardial tissue. All these considerations make EBM the 'gold standard' for diagnosis and treatment of myocarditis. ${ }^{4,21}$

In our study, LV biopsy has been revealed safe even in patients with severely compromised and electrically unstable ventricle being followed by no complications. 
Table I Baseline clinical parameters and immunological pattern of Myocarditis-necrotizing coronary vasculitis patients compared with Myocarditis patients and normal controls

\begin{tabular}{|c|c|c|c|c|}
\hline Patients' characteristics & $\begin{array}{c}\text { Myocarditis-NCV } \\
\text { pts, } n=30\end{array}$ & $\begin{array}{c}\text { Myocarditis } \\
\text { pts, } n=60\end{array}$ & $\begin{array}{c}\text { Controls, } \\
n=60\end{array}$ & $\begin{array}{l}\text { Overall } \\
P \text {-values }\end{array}$ \\
\hline Age (years) & $47.7 \pm 15.0$ & $49.3 \pm 14.5$ & $48 \pm 15.8$ & 0.864 \\
\hline \multirow[t]{3}{*}{ Sex } & $18 M(60 \%)$ & $37 M(61 \%)$ & $19 M(63 \%)$ & \\
\hline & & & & 0.198 \\
\hline & $12 F(40 \%)$ & $23 \mathrm{~F}(39 \%)$ & $11 \mathrm{~F}(37 \%)$ & \\
\hline \multicolumn{5}{|l|}{ Clinical manifestation } \\
\hline Heart failure & $26(87 \%)$ & $50(83 \%)^{c}$ & $0(0 \%)^{d}$ & 0.000 \\
\hline Electrical instability & $4(13 \%)$ & $10(17 \%)^{c}$ & $0(0 \%)^{d}$ & 0.064 \\
\hline \multicolumn{5}{|l|}{ 2D-echocardiography } \\
\hline LVEDD $(\mathrm{mm})$ & $57.2 \pm 8.6$ & $58.7 \pm 8.1^{c}$ & $47.3 \pm 11.9^{d}$ & 0.000 \\
\hline $\operatorname{LVESV}\left(\mathrm{mL} / \mathrm{m}^{2}\right)$ & $105.5 \pm 32.7$ & $105.4 \pm 33.1^{c}$ & $82.7 \pm 18.7^{d}$ & 0.001 \\
\hline $\operatorname{LVESV}\left(\mathrm{mL} / \mathrm{m}^{2}\right)$ & $76.8 \pm 33.8$ & $70.4 \pm 33.8^{c}$ & $31.7 \pm 6^{d}$ & 0.000 \\
\hline $\operatorname{LVEF}(\%)$ & $30 \pm 0.1$ & $34 \pm 1.3^{c}$ & $59 \pm 0.7^{d}$ & 0.000 \\
\hline MWT & $10.5 \pm 1.9$ & $11.4 \pm 2.9^{c}$ & $9.8 \pm 1.1$ & 0.008 \\
\hline \multicolumn{5}{|l|}{ Immunological pattern } \\
\hline Circulating IL-1b (pg/mL) & $2.82 \pm 8.0^{b}$ & $0.57 \pm 0.34$ & $0.35 \pm 0.24^{d}$ & 0.021 \\
\hline Circulating IL-8 (pg/mL) & $12.41 \pm 18.4$ & $8.42 \pm 4.6$ & $3.27 \pm 0.7^{d}$ & 0.002 \\
\hline Myocardial TLR4 & $3.21 \pm 0.65^{b}$ & $1.42 \pm 1.42^{c}$ & $0.06 \pm 0.1^{d}$ & 0.000 \\
\hline Anti-heart abs positivity (partially organ-specific pattern) & $27(90 \%)$ & $55(92 \%)^{c}$ & $0(0 \%)^{d}$ & 0.000 \\
\hline hs cTn $(\mu g / L)$ & $0.32 \pm 0.2^{b}$ & $0.1 \pm 0.14$ & $0.012 \pm 0.004^{d}$ & 0.000 \\
\hline
\end{tabular}

Regarding the cause of Myocarditis-NCV, infectious agents, autoreactive mechanisms, and autoimmune diseases were mostly involved.

Poorly opposable myocardial viral infection as those represented by HHV2 and co-infection by T. Gondii and ParvoB19 were among the deadly infectious causes.

The most common pathogenetic instance for Myocarditis-NCV was, however, a virus-negative immune-mediated inflammation. This included autoreactivity to myocardial antigens released after a chest trauma or newly generated haptens by drugs, as clozapine ${ }^{17}$ and clomipramine $^{18}$ administration. Primary autoimmune diseases like Systemic Lupus Erythematosus and Giant Cell myocarditis were among the most common specific entities while non-specific immune-mediated pathways were encountered in 13 cases. Severity of viral or non-viral myocardial and vessels inflammation suggests the occurrence of a cytokine storm. Indeed levels of interleukin $1 \beta$ were more pronounced in patients with Myocarditis-NCV compared with isolated myocarditis.

It is remarkable that all cases with immune-mediated MyocarditisNCV were virus-negative at myocardial PCR, had positive anti-heart Abs with partially organ-specific pattern, and showed overexpression of TLR4 at tissue immunohistochemistry. Particularly, the last aspect expresses tissue exposition of new antigens and the likely immunogenic origin of the inflammatory process. ${ }^{11}$
This pattern of differentiation with virus-induced MyocarditisNCV is crucial for treatment particularly whenever, because of limited PCR panel, the viral agent is missed.

Indeed, 22 Myocarditis-NCV patients (88\%) with immunemediated pathway among 25 treated with immunosuppression responded to the treatment with improvement of ejection fraction (EF) $\geq 10 \%$ and $77 \%$ of them manifested a complete recovery of cardiac function (see Figure 1). Immunosuppression included a various combination of steroids with azathioprine, cyclophosphamide, and high-dose immunoglobulins. In a patient with diabetes mellitus, inhibitor of interleukin $1 \beta$ (anakinra) was adopted. No major side effects from immunosuppression administration were registered.

Improvement or recovery of LV function was associated at control biopsy by disappearance of inflammatory infiltrates in the myocardium and intramural vessels that presented evidence of replacement fibrosis.

Therefore, Myocarditis-NCV clinically manifests as fulminant myocarditis, with severe haemodynamic compromise requiring aggressive inotropic support in the acute phase but with a beneficial response to immunosuppression. $^{22}$

Finally, in patients with virus-negative Myocarditis, immunosuppression induced an improvement of cardiac contractility in $86 \%$ of cases. These results were comparable with those already reported in the TIMIC trial. $^{8}$ 
Table 2 Association between in-hospital death and myocarditis with necrotizing coronary vasculitis in univariate and multivariable analysis

\begin{tabular}{|c|c|c|c|c|}
\hline Variable & Univariate & $P$-value & Multivariable & $P$-value ${ }^{a}$ \\
\hline NCV & $17.9(2.1-154)$ & 0.008 & $15.4(0.7-71)$ & 0.014 \\
\hline Age & $1.04(0.98-1.1)$ & 0.166 & & \\
\hline Female sex & $4.8(1.1-22)$ & 0.041 & $3.7(0.7-17.18)$ & 0.116 \\
\hline Heart failure & $1.32(0.15-11.6)$ & 0.803 & & \\
\hline Arrhythmic instability & $1.32(0.15-11.6)$ & 0.803 & & \\
\hline LVEF & $0.97(0.92-1.03)$ & 0.357 & & \\
\hline
\end{tabular}

LVEF, left ventricular ejection fraction; NCV, necrotizing coronary vasculitis.

${ }^{a} P$-value referred to comparison between three groups; $P$-value $<0.05$ was considered statistically significant.

\section{Conclusion}

Necrotizing coronary vasculitis can be histologically detected in up to $1.5 \%$ of patients with myocarditis. Necrotizing coronary vasculitis includes viral, auto-reactive, and autoimmune causes. Intra-hospital mortality is remarkably higher than for patients with isolated myocarditis. Identification of an immunologic pathway is associated with a beneficial response to immunosuppression.

\section{Supplementary material}

Supplementary material is available at European Heart Journal online.

\section{Funding}

The European Project ERA-CVD 'Transnational Research Projects on Cardiovascular Diseases' (JTC 2016 IKDT-IGCM) and by Italian Ministry of Health 'Ricerca corrente' IRCCS Spallanzani.

\section{Conflict of interest: none declared.}

\section{References}

1. Cooper LT Jr. Myocarditis. N Engl J Med 2009;360:1526-1538.

2. Schultheiss HP, Kühl U, Cooper LT. The management of myocarditis. Eur Heart J 2011;32:2616-2625.

3. Caforio AL, Calabrese F, Angelini A, Tona F, Vinci A, Bottaro S, Ramondo A, Carturan E, Iliceto S, Thiene G, Daliento L. A prospective study of biopsyproven myocarditis: prognostic relevance of clinical and aetiopathogenetic features at diagnosis. Eur Heart J 2007;28:1326-1333.

4. Caforio AL, Pankuweit S, Arbustini E, Basso C, Gimeno-Blanes J, Felix SB, Fu M, Heliö T, Heymans S, Jahns R, Klingel K, Linhart A, Maisch B, McKenna W, Mogensen J, Pinto YM, Ristic A, Schultheiss HP, Seggewiss H, Tavazzi L, Thiene G, Yilmaz A, Charron P, Elliott PM; European Society of Cardiology Working Group on Myocardial and Pericardial Diseases. Current state of knowledge on aetiology, diagnosis, management, and therapy of myocarditis: a position statement of the European Society of Cardiology Working Group on Myocardial and Pericardial Diseases. Eur Heart J 2013;34:2636-2648, 2648a-2648d.

5. Lang RM, Badano LP, Mor-Avi V, Afilalo J, Armstrong A, Ernande L, Flachskampf FA, Foster E, Goldstein SA, Kuznetsova T, Lancellotti P, Muraru D, Picard MH, Rietzschel ER, Rudski L, Spencer KT, Tsang W, Voigt JU. Recommendations for cardiac chamber quantification by echocardiography in adults: an update from the American Society of Echocardiography and the European Association of Cardiovascular Imaging. Eur Heart J Cardiovasc Imaging 2015;16:233-270.

6. Friedrich MG, Sechtem U, Schulz-Menger J, Holmvang G, Alakija P, Cooper LT, White JA, Abdel-Aty H, Gutberlet M, Prasad S, Aletras A, Laissy JP, Paterson I, Filipchuk NG, Kumar A, Pauschinger M, Liu P, International Consensus Group on Cardiovascular Magnetic Resonance in Myocarditis. Cardiovascular magnetic resonance in myocarditis: a JACC White Paper. J Am Coll Cardiol 2009;53: 1475-1487.
7. Pinto YM, Elliott PM, Arbustini E, Adler Y, Anastasakis A, Böhm M, Duboc D, Gimeno J, de Groote P, Imazio M, Heymans S, Klingel K, Komajda M, Limongelli G, Linhart A, Mogensen J, Moon J, Pieper PG, Seferovic PM, Schueler S, Zamorano JL, Caforio AL, Charron P. Proposal for a revised definition of dilated cardiomyopathy, hypokinetic non-dilated cardiomyopathy, and its implications for clinical practice: a position statement of the ESC working group on myocardial and pericardial diseases. Eur Heart J 2016;37:1850-1858.

8. Frustaci A, Russo MA, Chimenti C. Randomized study on the efficacy of immunosuppressive therapy in patients with virus-negative inflammatory cardiomyopathy: the TIMIC study. Eur Heart J 2009;30:1995-2002.

9. Chimenti C, Frustaci A. Contribution and risks of left ventricular endomyocardial biopsy in patients with cardiomyopathies: a retrospective study over a 28-year period. Circulation 2013;128:1531-1541.

10. Aretz HT, Billingham ME, Edwards WD, Factor SM, Fallon JT, Fenoglio JJ Jr, Olsen EG, Schoen FJ. Myocarditis: a histopathologic definition and classification. Am J Cardiol Pathol 1985;1:1-10.

11. Chimenti C, Verardo R, Scopelliti F, Grande C, Petrosillo N, Piselli P, De Paulis R, Frustaci A. Myocardial expression of Toll-like receptor 4 predicts the response to immunosuppressive therapy in patients with virus-negative chronic inflammatory cardiomyopathy. Eur J Heart Fail 2017;19:915-925.

12. Maron BJ, Towbin JA, Thiene G, Antzelevitch C, Corrado D, Arnett D, Moss AJ, Seidman CE, Young JB, American Heart Association; Council on Clinical Cardiology, Heart Failure and Transplantation Committee; Quality of Care and Outcomes Research and Functional Genomics and Translational Biology Interdisciplinary Working Groups; Council on Epidemiology and Prevention. Contemporary definitions and classification of cardiomyopathies: an American Heart Association Scientific Statement from the Council on Clinical Cardiology, Heart Failure and Transplantation Committee; Quality of Care and Outcome Research and Functional Genomics and Translational Biology Interdisciplinary Working Groups; and Council on Epidemiology and Prevention. Circulation 2006; 113:1807-1816.

13. Bordoni V, Sacchi A, Cimini E, Notari S, Grassi G, Tartaglia E, Casetti R, Giancola L, Bevilacqua N, Maeurer M, Zumla A, Locatelli F, De Benedetti F, Palmieri F, Marchioni L, Capobianchi MR, D'Offizi G, Petrosillo N, Antinori A, Nicastri E, Ippolito G, Agrati C. An inflammatory profile correlates with decreased frequency of cytotoxic cells in COVID-19. A Clin Infect Dis 2020;15:ciaa577.

14. Caforio AL, Bonifacio E, Stewart JT, Neglia D, Parodi O, Bottazzo GF, McKenna WJ. Novel organ-specific autoantibodies in dilated cardiomyopathy. J Am Coll Cardiol 1990;15:1527-1534.

15. Frustaci A, Chimenti C, Calabrese F, Pieroni M, Thiene G, Maseri A. Immunosuppressive therapy for active lymphocytic myocarditis: virological and immunologic profile of responders versus nonresponders. Circulation 2003;107: 857-863.

16. Frustaci A, Gentiloni N, Chimenti C, Natale L, Gasbarrini G, Maseri A. Necrotizing myocardial vasculitis in Churg-Strauss syndrome: clinic-histologic evaluation of steroids and immunosuppressive therapy. Chest 1998;114:1484-1489.

17. Pieroni M, Cavallaro R, Chimenti C, Smeraldi E, Frustaci A. Clozapine-induced hypersensitivity myocarditis. Chest 2004;126:1703-1705.

18. Frustaci A, Ferilli FA, Chimenti C. Hypersensitivity myocarditis and necrotizing coronary vasculitis by clomipramine causing steroid-sensitive cardiogenic shock. Circ Cardiovasc Imaging 2019;12:e008736.

19. Chimenti C, Nonno Topino DF, Abbate S, Licci I, Paglia S, Capobianchi MG, Petrosillo N, Frustaci A. Fatal myocardial co-infection by Toxoplasma gondii and Parvovirus B19 in an HIV patient. AIDS 2007;21:1383-1393. 
20. Francone M, Chimenti C, Galea N, Scopelliti F, Verardo R, Galea R, Carbone I, Catalano C, Fedele F, Frustaci A. CMR sensitivity varies with clinical presentation and extent of cell necrosis in biopsy-proven acute myocarditis. JACC CardiovasC Imaging 2014:7:254-263.

21. Cooper LT, Baughman KL, Feldman AM, Frustaci A, Jessup M, Kuhl U, Levine GN, Narula J, Starling RC, Towbin J, Virmani R, American Heart Association; American College of Cardiology; European Society of Cardiology. The role of endomyocardial biopsy in the management of cardiovascular disease: a scientific statement from the American Heart Association, the American College of Cardiology, and the European Society of Cardiology. Circulation 2007;116: 2216-2233.

22. McCarthy RE 3rd, Boehmer JP, Hruban RH, Hutchins GM, Kasper EK, Hare JM, Baughman KL. Long-term outcome of fulminant myocarditis as compared with acute (nonfulminant) myocarditis. N Engl J Med 2000;342:690-695. 